\title{
Fully-covered metal stents with endoscopic suturing vs. partially- covered metal stents for benign upper gastrointestinal diseases: a comparative study
}

\section{(๑) $\odot \ominus$}

\author{
Authors \\ Saowanee Ngamruengphong ${ }^{1,}{ }^{*}$, Reem Sharaiha ${ }^{2,}{ }^{,}$, Amrita Sethi ${ }^{3}$, Ali Siddiqui ${ }^{4}$, Christopher J. DiMaio ${ }^{5}$, Susana \\ Gonzalez ${ }^{5}$, Jason Rogart ${ }^{6}$, Sophia Jagroop ${ }^{7}$, Jessica Widmer ${ }^{7}$, Jennifer Im $^{5}$, Raza Abbas Hasan ${ }^{4}$, Sobia Laique ${ }^{4}$, Tamas \\ Gonda $^{3}$, John Poneros ${ }^{3}$, Amit Desai², Katherine Wong1, Vipin Villgran'1, Olaya Brewer Gutierrez¹, Majidah Bukhari', \\ Yen-I Chen ${ }^{1}$, Ruben Hernaez ${ }^{8}$, Yuri Hanada ${ }^{1}$, Omid Sanaei ${ }^{1}$, Amol Agarwal ${ }^{1}$, Anthony N. Kalloo ${ }^{1}$, Vivek Kumbhari ${ }^{1}$, \\ Vikesh Singh ${ }^{1}$, Mouen A. Khashab ${ }^{1}$
}

Institutions

1 Division of Gastroenterology, Johns Hopkins Hospital, Baltimore, Maryland, United States

2 Division of Gastroenterology and Hepatology, Weill Cornell Medical College, New York, New York, United States

3 Division of Digestive and Liver Diseases, Columbia University Medical Center, New York, New York, United States

4 Division of Gastroenterology and Hepatology, Thomas Jefferson University Hospital, Philadelphia, Pennsylvania, United States

5 Division of Gastroenterology, Icahn School of Medicine at Mount Sinai, New York, New York, United States

6 Capital Health Center for Digestive Health, Pennington, New Jersey, United States

7 North Shore University Hospital/ Long Island Jewish Medical Center, Forest Hills, New York, United States

8 Section of Gastroenterology and Hepatology, Department of Medicine, Baylor College of Medicine, Houston, Texas, United States

submitted 26.9.2017

accepted after revision 18.12 .2017

Bibliography

DOI https://doi.org/10.1055/s-0043-125363 |

Endoscopy International Open 2018; 06: E217-E223

(c) Georg Thieme Verlag KG Stuttgart · New York

ISSN 2364-3722

Corresponding author

Mouen Khashab, MD, Associate Professor of Medicine, Johns Hopkins Hospital, Division of Gastroenterology and Hepatology, 1800 Orleans Street, Sheikh Zayed Bldg. Suite 7125G, Baltimore, MD 21287

Fax: +1-443-683-8335

mkhasha1@jhmi.edu

\section{ABSTRACT}

Background and study aims Self-expandable metallic stents (SEMS) have been increasingly used in benign conditions (e.g. strictures, fistulas, leaks, and perforations). Fully covered SEMS (FSEMS) were introduced to avoid undesirable consequences of partially covered SEMS (PSEMS), but come with higher risk of stent migration. Endoscopic suturing (ES) for stent fixation has been shown to reduce migration of FSEMS. Our aim was to compare the outcomes of FSEMS with ES (FS/ES) versus PSEMS in patients with benign upper gastrointestinal conditions.

Patients and methods We retrospectively identified all patients who underwent stent placement for benign gastrointestinal conditions at seven US tertiary-care centers. Patients were divided into two groups: FSEMS with ES (FS/ ES group) and PSEMS (PSEMS group). Clinical outcomes between the two groups were compared.

Results A total of 74 (FS/ES 46, PSEMS 28) patients were included. On multivariable analysis, there was no significant difference in rate of stent migration between FS/ES (43\%) and PSEMS (15\%) (adjusted odds ratio 0.56; $95 \% \mathrm{Cl} 0.15-$ 2.00). Clinical success was similar [68\% vs. $64 \% ; P=0.81$ ]. Rate of adverse events (AEs) was higher in PSEMS group [13 (46\%) vs. 10 (21\%); $P=0.03)$. Difficult stent removal was higher in the PSEMS group $(n=5 ; 17 \%)$ vs. $0 \%$ in the FS/ES group; $P=0.005$.

Conclusions The proportion of stent migration of FS/ES and PSEMS are similar. Rates of other stent-related AEs were higher in the PSEMS group. PSEMS was associated with tissue ingrowth or overgrowth leading to difficult stent removal, and secondary stricture formation. Thus, FSEMS with ES for stent fixation may be the preferred modality over PSEMS for the treatment of benign upper gastrointestinal conditions.

* These authors contributed equally. 


\section{Introduction}

The use of self-expandable metal stents (SEMS) for endoscopic management of malignant upper gastrointestinal diseases is well-established [1]. There is a growing body of literature that supports the increasing use of SEMS for successful endoscopic management of benign upper gastrointestinal conditions, such as refractory strictures, leaks, fistulae, and spontaneous or iatrogenic perforations [2-8].

Partially-covered SEMS (PSEMS) have uncovered metal mesh ends that allow for tissue embedding in order to increase adherence to the intended location. However, when used for benign upper gastrointestinal conditions, PSEMS have been associated with serious AEs, such as challenging stent removal, due to the stents' inherent risk of stimulating mucosal hyperplasia, and subsequent stricture and fistulae formation $[9,10]$. Fully covered self-expandable metal stents (FSEMS) were introduced to avoid these AEs, but consequently are associated with increased risk of stent migration [11,12]. Despite above mentioned stent-related AEs, PSEMS is still commonly used for benign upper gastrointestinal conditions due to perception of its low risk of stent migration [3,11-14].

Stent migration remains a major limitation for FSEMS and can occur in up to one-third of cases [3, 8, 15-17]. It is associated with need for endoscopic re-intervention, increased healthcare costs, and AEs such as bowel perforation or obstruction [18]. As a result, various techniques have been developed to anchor stents. Endoscopic suturing (ES) has recently been described for stent fixation in order to reduce stent migration [19]. Recently, a 2016 multicenter study found that endoscopically sutured FSEMS placed for benign upper gastrointestinal conditions proved superior to non-sutured FSEMS in the prevention of stent migration [20].

Available data suggested that both endoscopic suturing for FSEMS and PSEMS reduce risk of stent migration for benign upper gastrointestinal diseases as compared to FSEMS alone without fixation. To date, comparative studies evaluating the outcomes of patients with benign upper gastrointestinal diseases treated with FSEMS and ES as compared to PSEMS are lacking. The primary objective of this study was to assess the frequency of stent migration among patients who underwent endoscopically sutured FSEMS placement and that of patients who underwent PSEMS placement. This study also sought to evaluate stent-related AEs and clinical success with respect to the underlying pathology. We hypothesized that FSEMS plus ES may have advantages over PSEMS in term of decreased risk of stent migration, and at the same time avoid unwanted AEs of tissue hyperplasia from PSEMS.

\section{Patients and methods}

In this retrospective cohort study, data were collected from the electronic medical records of patients who underwent endoluminal stent placement for benign upper gastrointestinal conditions, defined as strictures, fistulae, leaks and perforations, at seven U.S.tertiary care centers between January 1, 2007 and January 1, 2015. Inclusion criteria included patients who under- went either FSEMS placement with ES for stent fixation (FS/ES group) or PSEMS placement (PSEMS group). Exclusion criteria included patients who underwent FSEMS placement without ES or with an alternative method of stent fixation, and patients who underwent PSEMS with any form of stent fixation. The Institutional Review Board for each contributing center approved this study. The results of 44 patients in this study were previously included in a prior manuscript with long-term followup data provided [8].

FSEMS placement with ES was performed by methods as previously described $[19,21]$. Briefly, the OverStitch suturing device (Apollo Endosurgery, Austin, TX) is mounted on a doublechannel upper gastrointestinal endoscope. The suturing device is coupled with an accessory channel, through with the suture anchor with a detachable needle is threaded, as well as a handle that attaches to the port of the working channel. This configuration allows for increased dexterity in needle transfer and consequently of the suture through both stent and tissue. In this study, sutures were placed along the proximal metal stent loops and esophageal wall, with the number of sutures placed per the discretion of the endoscopist. For stent removal, the sutures were cut off with a loop cutter or endoscopic scissors and the stent handled with a snare or grasping forceps.

Data on patient factors, including demographics, details of the indication for stent placement such as size and location of the upper gastrointestinal condition, history of prior endoscopic stenting, and history of prior stent migration were collected. Data on stent factors, including type, diameter, length, location of placement with respect to the distal portion, and duration of use, calculated from the date of stent placement to the date of removal or spontaneous migration, were also collected. Patients were followed until date of last known followup.

\section{Definitions}

Clinical outcomes of patients in the FS/ES group were compared against those in the PSEMS group. Outcome measures included stent migration, defined as endoscopically or radiologically confirmed movement of the stent from the initial location such that the intended area to be covered was no longer covered; clinical success of stent placement; defined as endoscopically or radiologically confirmed resolution of the underlying benign upper gastrointestinal pathology following stent removal; and procedure-related AEs. Technical success was defined as the successful deployment of the stent in its proper position. Clinical success was defined as resolution of a stricture or closure of a fistula/leak/perforation as documented by clinical and endoscopic/radiological follow-up after stent removal. In the FS/ES group, technical success also included the successful deployment of suture to anchor the stent.

\section{Statistical analysis}

Categorical data were presented using frequency counts and percentages. Continuous data were presented as means \pm standard deviation or as median and interquartile range (IQR) (P25-P75). Between the two groups, chi-squared test and Fisher's exact test were used for categorical data comparisons, with 
t-test and Mann-Whitney $U$ test for continuous data comparisons, where appropriate. Logistic regression was used to analyze the effect of various factors on the odds of either stent migration or clinical success in the two groups. Multivariable modeling was used to examine the association between the two groups with respect to stent migration. $P$ values of $<0.05$ were considered significant. Statistical analyses were performed with SPSS v16.0 (Chicago, IL).

\section{Results}

A total of 74 (46 in the FS/ES group and 28 in the PSEMS group) patients (males $53 \%$, mean age 53 years) were included. Stent placement was performed for benign strictures in 32 (43\%) cases and leaks/fistulae/perforations in 42 (57\%) cases. In the FS/ES group, the mean number of sutures used for stent fixation [median (p25 and p75)] was $1(1-2)$ sutures. Technical success was $100 \%$ in both groups. Of these 74 patients, 51 (69\%) underwent one stenting procedure, 12 (16\%) underwent two procedures and the remaining patients underwent three or more procedures. The median duration that stents remained in position and were functional was 56 days (IQR 25-98) before they were removed at planned stent removal or migrated.

Overall, stent migration as determined endoscopically and/ or radiologically occurred in 19 patients (26\%) at a median of 56 days (IQR 16 - 102) after the index procedures. Besides stent migration, a total of $28 \mathrm{AEs}$ (31\%) occurred after stenting procedures.

The median follow - up after stent removal was 184 days (IQR 47-259 days). Clinical success with resolution of underlying condition was achieved in 49 patients (65\%), including 22 patients (67\%) with benign strictures and 27 patients (64\%) with leaks/fistulae/perforations.

\section{Comparative analysis: stent migration, clinical success and adverse events}

A total of 28 patients were in the PSEMS group and 46 patients were in the FS/ES group. Characteristics of the two study groups are shown in Table 1 . Both groups were similar in terms of age, gender, location of lesion, and location of distal end of the stent. There were no significant differences in the proportion of patients who had undergone prior endoscopic stent procedure or proportion of patients who had prior stent migration between the two groups. However, the FS/ES group had a higher proportion of patients with leaks/fistulae, a higher proportion of longer stents ( $>12 \mathrm{~cm}$ in length) and a higher proportion of larger diameter stent (>18 mm).

Stent migration occurred in $43 \%$ [12/28] the PSEMS group and $15 \%$ [7/46] in the FS/ES group after the index procedure $(P=0.01)$. Univariable analysis of factors associated with stent migration is shown in $>$ Table 2. Endoscopic suturing for stent fixation was significantly associated with decreased odds of stent migration as compared to PSEMS (odds ratio [OR] 0.23, $95 \% \mathrm{Cl} 0.08-0.72, P=0.01)$. Factors that were associated with increased odds of stent migration included stricture indication, shorter stents and smaller-diameter stents. In the multivariable analysis adjusting for indications, prior history of stent migra- tion, stent length, stent diameter and stent fixation; there was no statistically significant difference in the rate of stent migration between FS/ES and PSEMS (adjusted odds ratio 0.56; $95 \%$ Cl 0.15-2.00; $P=0.37$ ) ( $>$ Table 3).

The rate of AEs was higher in the PSEMS group: 13 (46\%) vs. $10(21 \%)$ in the FS/ES group $(P=0.03)$. D Table 4 lists the types of $A E s$ reported during the study period. Secondary stricture formation due to tissue ingrowth occurred in 3 patients (10\%) in the PSEMS group and none in the FS/ES group $(P=0.05)$. The strictures were successfully treated by endoscopic balloon dilation and/or stenting in all three patients. Tracheoesophageal fistula occurred in one patient in the PSEMS group.Surgery was recommended, but the patient refused. Perforation occurred in one patient in the FS/ES group during stent insertion and the patient underwent emergency surgery. In the FS/ES group, there were no AEs related to suture placement and/or suture removal. Difficult stent removal due to tissue ingrowth/ overgrowth was reported in 5 patients $(17 \%)$ in the PSEMS group which was higher than that of the FS/ES group $(0 \%)(P=$ $0.005)$. All of these 5 patients required stent-in-stent technique for removal of the embedded stents.

Clinical success after stent removal was achieved in 30 (64\%) patients in the FS/ES group and $19(68 \%)$ in the PSEMS group ( $P$ $=0.81)$. In logistic regression analysis of factors associated with clinical success, there was no statistically significant difference in clinical success between the type of stent (FSEMS with ES vs. PSEMS) (OR $0.8395 \% \mathrm{Cl} 0.31-2.25 ; P=0.72$ ) ( $>$ Table 5). However, the PSEMS group required significantly more procedures than FS/ES group $(1.86 \pm 0.9$ vs. $1.26 \pm 0.6 ; P=0.006)$ to achieve clinical response.

\section{Discussion}

In this large multicenter retrospective study, we found that rate of stent migration with endoscopically sutured FSEMS in benign upper gastrointestinal diseases was similar to that of PSEMS. However, rates of other stent-related AEs were higher in the PSEMS group. PSEMS was associated with tissue ingrowth or overgrowth leading to difficult stent removal, secondary stricture formation and associated with increased the number of required endoscopic sessions. Thus, FSEMS with endoscopic suturing for stent fixation may be the preferred modality over PSEMS for the treatment of benign upper gastrointestinal conditions.

Endoscopic stent placement with SEMS has become a viable minimally invasive treatment option for various benign upper gastrointestinal conditions. However, the major unresolved problems of stent therapy are stent migration and tissue ingrowth or overgrowth. Fully covered metal stents, as compared to non-fully covered metal stents, is associated with increased risk of stent migration because of the lack of traction on the esophageal wall $[1,3,17,22]$. Tissue hyperplasia or new stricture formation has been reported as high as $41 \%$ to $53 \%$ after PSEMS placement [12,23]. Ingrowth or overgrowth of the granulation tissue either through the stent or at either end of the uncovered stent lead to stent embedding and subsequent difficult stent removal. In addition, the stent, particularly at 
- Table 1 Baseline patient characteristics.

\begin{tabular}{|c|c|c|c|}
\hline & PSEMS group $(n=28)$ & FS/ES group $(n=46)$ & $P$ value \\
\hline Age, mean $\pm S D$, years & $50 \pm 15$ & $54 \pm 17$ & 0.38 \\
\hline Male sex, n (\%) & $12(43 \%)$ & $21(46 \%)$ & 0.82 \\
\hline \multicolumn{3}{|l|}{ Site of pathology, $n$ (\%) } & \multirow[t]{4}{*}{0.33} \\
\hline - Esophagus & $21(75 \%)$ & $39(85 \%)$ & \\
\hline - Stomach & $6(21 \%)$ & $7(15 \%)$ & \\
\hline - Duodenum & $1(4 \%)$ & $0(0)$ & \\
\hline History of prior stenting, n (\%) & $13(46 \%)$ & $13(26 \%)$ & 0.08 \\
\hline History of prior stent migration, $\mathrm{n}(\%)$ & $10(36 \%)$ & $8(19 \%)$ & 0.12 \\
\hline \multicolumn{3}{|l|}{ Distal end of stent, $\mathrm{n}(\%)$} & \multirow[t]{3}{*}{0.72} \\
\hline - In the esophagus & $4(14 \%)$ & $5(11 \%)$ & \\
\hline - Below the gastroesophageal junction & $24(86 \%)$ & $41(89 \%)$ & \\
\hline \multicolumn{3}{|l|}{ Indication for stent placement } & \multirow[t]{11}{*}{0.001} \\
\hline - Stricture, n (\%) & $19(68 \%)$ & $13(28 \%)$ & \\
\hline - Anastomotic stricture & 11 & 2 & \\
\hline - Radiation & 1 & 3 & \\
\hline - Peptic stricture & 1 & 2 & \\
\hline - Other causes & 6 & 6 & \\
\hline - Leak/ fistula/ perforation, n (\%) & $9(32 \%)$ & $33(72 \%)$ & \\
\hline - Post-bariatric surgery & 4 & 22 & \\
\hline - Anastomotic leak & 0 & 7 & \\
\hline - latrogenic perforation & 1 & 2 & \\
\hline - Other causes & 4 & 2 & \\
\hline \multicolumn{3}{|l|}{ Stent diameter, $n(\%)$ (missing; $n=1$ ) } & \multirow[t]{3}{*}{0.001} \\
\hline . $\leq 18 \mathrm{~mm}$ & $22(79 \%)$ & $16(36 \%)$ & \\
\hline . $>18 \mathrm{~mm}$ & $6(21 \%)$ & $29(64 \%)$ & \\
\hline \multicolumn{3}{|l|}{ Stent length } & \multirow[t]{3}{*}{0.02} \\
\hline - $\leq 10 \mathrm{~cm}$ & $9(32 \%)$ & $4(9 \%)$ & \\
\hline . $>10 \mathrm{~cm}$ & $19(68 \%)$ & $42(91 \%)$ & \\
\hline
\end{tabular}

the uncovered ends, cause mechanical injury on the esophageal wall and fibrosis resulting in new stricture formation. Secondary stricture requires additional endoscopic intervention with dilation and/or stenting.

Removal of embedded PSEMS is technically challenging. Serious AEs, such as esophageal perforation, avulsion, fistula, have been reported following removal of the embedded PSEMS [9, 13]. The "stent-in-stent technique" has been described as a rescue technique for removal of the embedded PSEMS.In this technique, a fully covered self-expandable stent is placed inside the PSEMS to induce pressure necrosis of ingrown tissue. Subsequent removal of both stents is performed after a period of $10-14$ days. This technique is highly effective for removal of the embedded stent. However, it requires additional stents, another procedure and increased costs in order to remove a PSEMS [14, 24].

Due to the stent-related AEs described above, the use of PSEMS in the treatment of benign diseases is controversial. Despite these drawbacks, some experts recommended PSEMS for benign upper gastrointestinal diseases such as refractory strictures, leaks, fistulas and perforations; especially in patients with history of fully-covered stent migration or patients at high risk of catastrophic AEs with stent migration [3, 14].

PSEMS are associated with lower rates of stent migration, ranges from $9 \%$ to $31 \%$ in benign upper gastrointestinal conditions [12,23]. In contrast, the rate of migration of FSEMS is as 
- Table2 Univariable logistic regression analysis of factors associated with stent migration.

\begin{tabular}{|c|c|c|c|}
\hline Characteristics & Odds ratio & $95 \%$ confidence interval & $P$ value \\
\hline Age & 1.003 & $0.97-1.03$ & 0.86 \\
\hline Sex (male vs. female ${ }^{1}$ ) & 2.06 & $0.18-2.06$ & 0.18 \\
\hline Indications (strictures vs. leaks/fistulas/perforations ${ }^{1}$ ) & 4.11 & $1.34-12.53$ & 0.01 \\
\hline Prior history of stent migration (yes vs. no ${ }^{1}$ ) & 2.12 & $0.67-6.67$ & 0.19 \\
\hline Stent length ( $\leq 10 \mathrm{~cm}$ vs. $>10 \mathrm{~cm}^{1}$ ) & 4.76 & $1.35-16.79$ & 0.01 \\
\hline Stent type (FS/ES vs. PSEMS ${ }^{1}$ ) & 0.23 & $0.08-0.72$ & 0.01 \\
\hline Stent diameter ( $\leq 18 \mathrm{~mm}$ vs. $>18 \mathrm{~mm}^{1}$ ) & 5.05 & $1.48-17.25$ & 0.01 \\
\hline Distal end of stent (in the esophagus ${ }^{1}$ vs. below the gastroesophageal junction) & 1.24 & $0.23-6.56$ & 0.80 \\
\hline Dilation of stricture before stent placement (yes vs. no ) (in stricture group) & 0.84 & $0.21-3.46$ & 0.81 \\
\hline
\end{tabular}

- Table 3 Multivariable logistic regression analysis of factors associated with stent migration.

\begin{tabular}{|c|c|c|c|}
\hline Characteristics & Adjusted odds ratio ${ }^{1}$ & $95 \%$ confidence interval & $P$ value \\
\hline Indications (strictures vs. leaks/fistulas/perforations ${ }^{2}$ ) & 1.42 & $0.32-6.26$ & 0.64 \\
\hline Prior history of stent migration (yes vs. $\mathrm{no}^{2}$ ) & 0.57 & $0.16-2.12$ & 0.41 \\
\hline Stent length ( $\leq 10 \mathrm{~cm}$ vs. $\left.>10 \mathrm{~cm}^{2}\right)$ & 2.76 & $0.65-11.63$ & 0.16 \\
\hline Stent diameter ( $\left(\leq 18 \mathrm{~mm}\right.$ vs. $\left.>18 \mathrm{~mm}^{2}\right)$ & 2.18 & $0.45-10.37$ & 0.32 \\
\hline Stent type (FS/ES vs. PSEMS²) & 0.56 & $0.15-2.00$ & 0.37 \\
\hline
\end{tabular}

- Table4 Adverse events after treatment with endoscopic stenting (ES) for FCSEMS and PSEMS for benign upper gastrointestinal conditions.

\begin{tabular}{|l|l|l|}
\hline Adverse events & PSEMS group & FS/ES group \\
\hline Number of stent procedures & 28 & 46 \\
\hline Total adverse events, $\mathrm{P}(\%)$ & $13(46 \%)$ & $10(21 \%)$ \\
\hline - Chest/abdominal pain & 1 & 7 \\
\hline - Stent obstruction due to tissue overgrowth & 1 & 0 \\
\hline - Hemorrhage & 2 & 1 \\
\hline - Stricture formation due to the stent & 3 & 0 \\
\hline - Perforation & 0 & 1 \\
\hline - Aspiration pneumonia & 0 & 1 \\
\hline - Tracheoesophageal fistula & 0 & 0 \\
\hline - Difficulty removing the embedded stent & 1 & $0(0 \%)$ \\
\hline - Required stent-in-stent technique for stent removal & $5(17 \%)$ & 0 \\
\hline PSEMS, partially-covered self-expandable metallic stents; FS/ES, FSEMS with endoscopic suturing.
\end{tabular}

high as $26 \%-36 \%[6,16,17,22]$. Thus, various techniques have been developed in attempts to prevent migration of FSEMS, such as stent fixation with through-the-scope clips [25], over- the-scope clips [26] and endoscopic suturing [8, 19]. In a proof of biomechanical ex vivo study, endoscopic suturing provided significantly higher migration resistance compared with clip 
- Table 5 Univariable logistic regression analysis of factors associated with clinical success.

\begin{tabular}{|c|c|c|c|}
\hline Characteristics & Odds ratio & $95 \%$ confidence interval & $P$ value \\
\hline Indications (strictures vs. leaks/fistulas/perforations ${ }^{1}$ ) & 1.11 & $0.42-2.90$ & 0.83 \\
\hline Prior history of stent migration (yes vs. no ${ }^{1}$ ) & 1.53 & $0.51-4.62$ & 0.49 \\
\hline Stent length ( $\leq 10 \mathrm{~cm}$ vs. $\left.>10 \mathrm{~cm}^{1}\right)$ & 0.58 & $0.16-2.14$ & 0.42 \\
\hline Stent type (FS/ES vs. PSEMS ${ }^{1}$ ) & 0.83 & $0.31-2.25$ & 0.72 \\
\hline Stent diameter ( $\leq 18 \mathrm{~mm}$ vs. $\left.>18 \mathrm{~mm}^{1}\right)$ & 1.04 & $0.40-2.69$ & 0.93 \\
\hline Distal end of stent (in the esophagus* vs. below the gastroesophageal junction) & 0.20 & $0.02-1.74$ & 0.14 \\
\hline Dilation of stricture before stent placement (yes vs. no ) (in stricture group) & 1.96 & $0.49-7.88$ & 0.34 \\
\hline
\end{tabular}

fixation or stent placement without fixation [27]. This technique is relatively simple and easy to use. The reported technical success rate of endoscopic suturing for stent anchorage is $100 \%$ and the average time for stent fixation is only 12.5 minutes $[19,28]$.

A recent multicenter study, including 125 patients with benign upper gastrointestinal conditions has shown that endoscopic suturing for fixation of FSEMS is safe and associated with decreased migration rate compared to no stent fixation ( $16 \%$ vs. $33 \% ; P=0.03$ ). Endoscopic suturing for stent fixation appeared to protect against stent migration in patients with a history of stent migration (adjusted odds ratio of $0.09 ; 95 \% \mathrm{Cl}$ $0.02-0.47 ; P=0.002$ ). It may also improve clinical response, likely because of the reduction in stent migration [8].

Given that endoscopic suturing is safe, effective to prevent stent migration and be able to avoid AEs from tissue ingrowth or overgrowth from PSEMS, using FSEMS plus ES for stent fixation should be a preferred alternative to PSEMS in benign upper gastrointestinal diseases.

There are some limitations to this study. This was a retrospective and some detail data including procedural information were not available. Additionally, the decision to select treatment options either endoscopic suturing for stent fixation or placement of PSEMS was on the basis of endoscopist preference and device availability. This may introduce selection bias. Finally, optimal technique of endoscopic suturing has not been clearly defined. There were minor variations in the suturing technique such as number of suture or use of an endoscopic tissue grasper device during suturing, which could lead to differences in holding strength of suture anchors and its efficacy in preventing stent migration. The efficacy of suturing on prevention of stent migration may be affected by the learning curve. Because each center performed only a small number of suturing cases, we are unable to assess the learning curve effect on stent migration outcomes.

\section{Conclusion}

In conclusion, in benign upper gastrointestinal diseases, treatment with FSEMS with ES for stent fixation appears to be equally effective to PSEMS in term of preventing stent migration and achieving clinical success. Additionally, FSEMS with ES is safer and avoids AEs related to PSEMS, particularly tissue ingrowth or overgrowth, new stricture formation and difficulties with stent removal. FSEMS with ES may be the preferred treatment options to PSEMS for benign upper gastrointestinal conditions. Future large prospective studies aiming to assess the efficacy of endosuturing for the prevention of stent migration and cost effectiveness analysis of this technique are warranted.

\section{Competing interests}

Dr. Khashab is a consultant for Boston Scientific. Dr. Sethi acts as a consultant for Boston Scientific and Xlumera and has received travel expenses for unrelated meetings from Beacon Endoscope and Mauna Kea Technologies. Dr. Kalloo is a founding member, equity Holder and consultant for Apollo Endosurgery. Dr. Poneros acts as a consultant for Boston Scientific. Dr. Rogart acts as a consultant for Boston Scientific. Dr. DiMaio is a consultant and speaker for Boston Scientific. Dr. Singh is a consultant for Abbvie, D-Pharm, and Santarus. Dr. Kumbhari is a consultant for Boston Scientific, Apollo Endosurgery and Medtronic.

\section{References}

[1] Sharma P, Kozarek R. Role of esophageal stents in benign and malignant diseases. Am J Gastroenterol 2010; 105: 258 - 273 quiz 274

[2] Salminen P, Gullichsen R, Laine S. Use of self-expandable metal stents for the treatment of esophageal perforations and anastomotic leaks. Surg Endosc 2009; 23: 1526 - 1530

[3] Sharaiha RZ, Kim KJ, Singh VK et al. Endoscopic stenting for benign upper gastrointestinal strictures and leaks. Surg Endosc 2014; 28: $178-184$

[4] Thomas T, Abrams KR, Subramanian V et al. Esophageal stents for benign refractory strictures: a meta-analysis. Endoscopy 2011; 43: $386-393$

[5] Fuccio L, Hassan C, Frazzoni L et al. Clinical outcomes following stent placement in refractory benign esophageal stricture: a systematic review and meta-analysis. Endoscopy 2016; 48: 141 - 148 
[6] van Boeckel PG, Sijbring A, Vleggaar FP et al. Systematic review: temporary stent placement for benign rupture or anastomotic leak of the oesophagus. Aliment Pharmacol Ther 2011; 33: 1292 - 1301

[7] van Heel NC, Haringsma J, Spaander MC et al. Short-term esophageal stenting in the management of benign perforations. Am J Gastroenterol 2010; 105: 1515-1520

[8] Ngamruengphong S, Sharaiha RZ, Sethi A et al. Endoscopic suturing for the prevention of stent migration in benign upper gastrointestinal conditions: a comparative multicenter study. Endoscopy 2016; 48: $802-808$

[9] Hirdes MM, Vleggaar FP, Van der Linde K et al. Esophageal perforation due to removal of partially covered self-expanding metal stents placed for a benign perforation or leak. Endoscopy 2011; 43: 156 159

[10] Gangloff A, Lecleire S, Di Fiore A et al. Fully versus partially covered self-expandable metal stents in benign esophageal strictures. Diseases of the esophagus: official journal of the International Society for Diseases of the Esophagus 2015; 28: 678-683

[11] van Boeckel PG, Dua KS, Weusten BL et al. Fully covered self-expandable metal stents (SEMS), partially covered SEMS and self-expandable plastic stents for the treatment of benign esophageal ruptures and anastomotic leaks. BMC Gastroenterol 2012; 12: 19

[12] Seven G, Irani S, Ross AS et al. Partially versus fully covered self-expanding metal stents for benign and malignant esophageal conditions: a single center experience. Surg Endosc 2013; 27: 2185 - 2192

[13] Baron TH. Esophageal avulsion following removal of a partially covered esophageal stent: lessons learned 10 years later. Clin Gastroenterol Hepatol 2012; 10: e1

[14] DaVee T, Irani S, Leggett CL et al. Stent-in-stent technique for removal of embedded partially covered self-expanding metal stents. Surg Endosc 2016; 30: 2332-2341

[15] Wagh MS, Forsmark CE, Chauhan S et al. Efficacy and safety of a fully covered esophageal stent: a prospective study. Gastrointest Endosc 2012; 75: 678-682

[16] Buscaglia JM, Ho S, Sethi A et al. Fully covered self-expandable metal stents for benign esophageal disease: a multicenter retrospective case series of 31 patients. Gastrointest Endosc 2011; 74: 207-211
[17] Bakken JC, Wong KeeSong LM, de Groen PC et al. Use of a fully covered self-expandable metal stent for the treatment of benign esophageal diseases. Gastrointest Endosc 2010; 72: 712 - 720

[18] Ko HK, Song HY, Shin JH et al. Fate of migrated esophageal and gastroduodenal stents: experience in 70 patients. J Vasc Interv Radiol 2007; 18: $725-732$

[19] Kantsevoy SV, Bitner M. Esophageal stent fixation with endoscopic suturing device (with video). Gastrointest Endosc 2012; 76: 1251 1255

[20] Ngamruengphong S, Sharaiha RZ, Sethi A et al. Endoscopic suturing for the prevention of stent migration in benign upper gastrointestinal conditions: a comparative multicenter study. Endoscopy 2016; 48: 808

[21] Sharaiha RZ, Kumta NA, Doukides TP et al. Esophageal Stenting With Sutures: Time to Redefine Our Standards? Journal of clinical gastroenterology 2015; 49: e57-60

[22] Eloubeidi MA, Talreja JP, Lopes TL et al. Success and complications associated with placement of fully covered removable self-expandable metal stents for benign esophageal diseases (with videos). Gastrointest Endosc 2011; 73: 673-681

[23] Sandha GS, Marcon NE. Expandable metal stents for benign esophageal obstruction. Gastrointest Endosc Clin N Am 1999; 9: 437 - 446

[24] Hirdes MM, Siersema PD, Houben MH et al. Stent-in-stent technique for removal of embedded esophageal self-expanding metal stents. Am J Gastroenterol 2011; 106: 286-293

[25] Vanbiervliet G, Filippi ], Karimdjee BS et al. The role of clips in preventing migration of fully covered metallic esophageal stents: a pilot comparative study. Surg Endosc 2012; 26: 53 - 59

[26] Irani S, Baron TH, Gluck M et al. Preventing migration of fully covered esophageal stents with an over-the-scope clip device (with videos). Gastrointest Endosc 2014; 79: 844 - 851

[27] Rieder E, Dunst CM, Martinec DV et al. Endoscopic suture fixation of gastrointestinal stents: proof of biomechanical principles and early clinical experience. Endoscopy 2012; 44: 1121 - 1126

[28] Fujii LL, Bonin EA, Baron TH et al. Utility of an endoscopic suturing system for prevention of covered luminal stent migration in the upper gastrointestinal tract. Gastrointest Endosc 2013; 78: 787-793 